Estudios Románicos, Volumen 29, 2020, pp. 195-208

ISSN: 0210-4911

eISSN: 1989-614X

DOI: https://doi.org/10.6018/ER.415741

\title{
EL LIBRO DE CINCUENTA ROMANCES: CONSTITUCIÓN Y CONTENIDO
}

(The Libro de cincuenta romances: constitution and content)

\author{
Mario Garvin* \\ Universität Konstanz
}

\begin{abstract}
The history of the printed circulation of the Romancero has been understood as a development from the cancioneros and pliegos sueltos (Chapbooks) to bigger collections of romances, like the Cancionero de romances. Historically speaking, not much attention has been paid to the Libro de cincuenta romances, which does not fit this development. The accepted publication date, that is, ca. 1525, and the fifty romances mentioned in the title make this book very relevant to the history of the publication. In this article, the constitution and the content of the preserved leaves are analysed to deepen the hypothetical content of the volume. It demonstrates that the various forms of the Romancero should not be understood as part of a homogeneous development, but in the context of their appearance.
\end{abstract}

Keywords: Libro de cincuenta romances; Romancero; Textual criticism; Textual bibliography, Chapbook.

Resumen: La historia de la transmisión impresa del romancero ha sido entendida como una evolución que iría desde los cancioneros y los pliegos sueltos hasta colecciones mayores, como el Cancionero de romances. Históricamente, no se ha prestado demasiada atención al Libro de cincuenta romances, que no encaja en este desarrollo. $\mathrm{Su}$ fecha de publicación - se acepta que se imprimió ca. 1525 - y los cincuenta romances en el título, lo convierten en una obra de absoluta relevancia para la evolución del género. En este artículo, se analizan la constitución y el contenido de las pocas hojas conservadas para profundizar en el hipotético contenido del volumen. Así se demuestra que las varias formas de aparición del romancero no deben ser comprendidas como un desarrollo homogéneo, sino en dependencia de su(s) contexto(s) de aparición.

${ }^{*}$ Dirección para correspondencia: Universität Konstanz, SLI. Universitätsstraße 10. Fach 171. 78464 Constanza, Alemania. 
Palabras clave: Libro de cincuenta romances; Romancero; Crítica textual; Bibliografía analítica; Pliego suelto.

Dentro de la transmisión impresa del romancero, el Libro de cincuenta romances parece constituir desde un punto de vista formal una anomalía respecto al resto de transmisores. Según se suele aceptar, en el siglo XVI esta se lleva a cabo fundamentalmente mediante tres tipos de transmisores: cancioneros, pliegos sueltos y romanceros. Este consenso queda manifiesto tanto en el empleo de esta terminología en los principales instrumentos bibliográficos de trabajo en este campo de la investigación filológica, como en los numerosos trabajos académicos que a él se dedican ${ }^{1}$.

Cronológicamente, el orden en que los he nombrado - cancionero, pliego y romancero - es también el orden de aparición de los testimonios. Los primeros romances impresos documentados aparecen en cancioneros de autor, como el de Juan del Encina, el de Iñigo López de Mendoza o el de Fray Ambrosio Montesinos. Estos cancioneros son más o menos voluminosos y en ellos los romances tienen, estadísticamente hablando, un papel casi meramente testimonial. De hecho, incluso en el gran cancionero colectivo de comienzos de siglo que es el Cancionero general (Valencia, $1511^{2}$ ), su presencia aún es comparativamente baja. Disponen allí por primera vez, es cierto, de una sección propia, pero en ella contamos únicamente 37 romances para un total de composiciones que supera el millar, y contando también aquellos romances que aparecen dispersos - es decir, fuera de la sección de romances propiamente dicha (En los más altos confines y Cabe la isla del Elba) -, no llegamos a la cuarentena.

El siguiente tipo de testimonio en aparecer a escena son los pliegos sueltos. Este es un punto complejo, expuesto a malinterpretaciones: existen ya antes del Cancionero general pliegos sueltos poéticos, es decir - simplificando mucho el problema de la definición de estos impresos ${ }^{3}$ - una hoja de papel a tamaño natural doblada un número indeterminado de veces, e incluso antes de 1511 hallamos ya algunos romances en pliegos sueltos (p. ej. De septiembre se contaba, RM1171), pero no es hasta principios de esa segunda década del Quinientos que puede fecharse el inicio sistemático de una difusión de romances en este tipo de impresos. Tal inicio, además, puede localizarse y atribuirse con notable precisión a la imprenta sevillana de Jacobo Cromberger, desde donde, según todo parece indicar, se inicia la publicación de textos romancísticos y se fija - tras una breve fase experimental - el modelo material más o menos estandarizado para este tipo de pliegos ${ }^{4}$.

\footnotetext{
$1 \quad$ Me refiero, obviamente al Diccionario de pliegos sueltos poéticos (Rodríguez-Moñino 1970 y 1997) y al Manual bibliográfico de Cancioneros y Romanceros (Rodríguez-Moñino 1973), pero la distinción entre estos tipos de transmisores está presente también en Piacentini (1981 y 1986).

2 Hay edición facsímil (Rodríguez-Moñino 1958) y una edición crítica moderna a cargo de Joaquín González Cuenca (2004).

3 El trabajo clásico al respecto sigue siendo el de Infantes (1988) que debe completarse con trabajos posteriores del propio Infantes (1989) y los trabajos de Puerto Moro (2006 y 2012), así como Garvin (2007: 97-111).

$4 \quad$ Además de los ya citados trabajos de Puerto Moro, es imprescindible para esta fase evolutiva del pliego suelto el trabajo de Vicenç Beltran (2006). Para los pliegos sevillanos de esa época, Garvin (2019).
} 
Desde un punto de vista formal, los pliegos con romances salidos de este taller sevillano no son, especialmente en los primeros años, homogéneos, ya que encontramos pliegos en folio y en cuarto, con grabados y sin grabados, con el texto a tres y a dos columnas. Pero pronto esos pliegos - no solo los de Cromberger, sino el pliego poético en general - adquieren las que serán sus características más comunes: una especie de "pliego modelo", que sería en cuarto, de cuatro hojas, con un título, generalmente un grabado y el texto a dos columnas. Norton y Wilson ya caracterizaron en 1969 - un año antes de la aparición del Diccionario de Rodríguez-Moñino - ese pliego tipo en base a "its quarto format, the restriction of its text to a single folded sheet, its title embellished by an irrelevant reused woodcut with the text beginning immediately below in two columns, its gothic types, and its lack of any indication of place, printer or date" (1969: 5) y medio siglo después, pese a los numerosos descubrimientos posteriores ${ }^{5}$, parecen conservar la razón en ese punto.

Finalmente, hacia mediados de la centuria aparecen una serie de compilaciones que aúnan rasgos de los dos transmisores anteriores sin ser iguales a ninguno de ellos. $\mathrm{Me}$ refiero, claro está, a los romanceros. No existe, que yo sepa, un intento de definición claro de qué son exactamente estos romanceros, aunque evidentemente parecen definirse en función, por un lado, de su contenido y, por otro, de sus características materiales. Romanceros serían por tanto aquellos volúmenes que, a partir de finales de la década de los cuarenta, comenzando por el Cancionero de romances, los Romances de Sepúlveda o las tres partes de la Silva, transmiten casi exclusivamente romances. Digo "casi" porque en varios de estos testimonios encontramos textos que no son romances, pero entiendo - y los títulos de las obras son suficientemente explícitos - que su objetivo editorial fundamental es la transmisión de textos romancísticos. Materialmente, son volúmenes de una extensión notable, de entre unas 150 (la tercera parte de la Silva tiene 154 hojas) y 300 hojas (como sucede, por ejemplo, con la edición de 1550 del Cancionero de romances), o sea, de aproximadamente unas 200 hojas de media. Son todos volúmenes en doceavo, formato reducido que, al parecer, se populariza desde Amberes con el Cancionero de romances y que permite intuir ciertas prácticas de lectura.

Como se habrá notado, dentro de este sucinto panorama los ejes sobre los que se articula la distinción entre uno y otro tipo de testimonios son básicamente su constitución tipográfica y su contenido. Los cancioneros y los romanceros comparten ciertos rasgos materiales frente a los pliegos sueltos, ya que dentro de su heterogeneidad de contenido son volúmenes unitarios compuestos de varios pliegos, mientras que respecto al contenido, el carácter eminentemente misceláneo de los cancioneros crea un espacio compartido entre el pliego suelto con romances y el romancero.

Pues bien, no resulta nada sencillo situar al Libro de cincuenta romances en esta evolución, del mismo modo que resulta muy complejo decidir qué tipo de transmisor es exactamente. Es obvio, por otra parte, que el carácter eminentemente fragmentario de su transmisión dificulta aún más esta tarea. Pero vayamos por partes. Se trata de

5 Compilados en el Suplemento al Nuevo Diccionario, (Askins; Infantes 2014). 
una obra impresa en Barcelona por Carles Amorós hacia $1525^{6}$, de la que se conservan solamente cuatro páginas, si bien hay acuerdo entre la crítica en considerar que estamos frente a los restos de un volumen mayor, de varios pliegos, algo que coincide con lo que suele esperarse en un impreso que lleva la denominación de Libro. En cuanto al contenido, sin embargo, el impreso pone ya desde el mismo título el acento sobre los romances, aunque - como veremos más abajo - no podemos pasar por alto que estos van acompañados de sus villancicos y desechas.

Y aquí es donde reside el carácter anómalo de esta obra o, mejor dicho, el motivo por el cual se considera anómalo al Libro: contiene, por un lado, muchos más romances que el pliego con mayor número de ellos; por otro lado, sin embargo, sus características materiales, que en gran parte hemos de deducir de las hojas conservadas, se corresponden más a un pliego que a los romanceros que mencionábamos hace un momento. Visto desde esa perspectiva, efectivamente, el Libro de cincuenta romances aparece en el panorama editorial de la primera mitad del Quinientos casi como un islote, sin que se sepa demasiado bien si debe considerarse como un intento temprano de compilación romancística que quedó sin continuadores hasta que apareció el Cancionero de Nucio, una suerte de romancero avant la lettre o si, por el contrario, es una pieza única que nos está indicando que el Cancionero de Amberes es menos original de lo que se suele creer y que si no conocemos mejor el panorama editorial de la primera mitad del siglo es únicamente debido a las pérdidas sufridas.

Esta duda sobre cómo considerar al Libro historiográficamente, se extiende a su propia materialidad, ya que recordemos que aparece registrado tanto en el Diccionario de pliegos sueltos (RM936) como en el Manual bibliográfico de cancioneros y romanceros (Rodríguez-Moñino 1970: 170, n 28), lo que no deja de ser una prueba más de su carácter anómalo y de las dudas de la crítica sobre cómo clasificarlo.

La cuestión que interesa abordar ahora, por tanto, es si partiendo de estas cuatro hojas podemos entrever prácticas editoriales más comunes de lo que los testimonios conservados hacen suponer. Ya de entrada, un argumento en favor de que el Libro de cincuenta romances no es una aparición tan aislada como pudiera parecer en un primer momento es que se le puede suponer como mínimo una edición anterior. En las cuatro hojas conservadas de la edición barcelonesa se contienen diez textos - seis romances, tres villancicos y una deshecha -, pero en la portada se indica que hay en el Libro muchos romances "nueuamente añadidos", lo que, como ya notó Rodríguez-Moñino al editar los pliegos de Morbecq, implica que el Libro conservado "por lo menos, es una segunda edición añadida" (1962: 49). Pocos años después, en 1969, en su estudio sobre la Silva de 1561, Rodríguez-Moñino propone incluso un lugar de impresión y una explicación socioliteraria a su aparición, al escribir que esa primera edición del Libro podría haber sido impresa en Valencia como una "derivación del apartado de romances

6 Debemos añadir, además, que esas cuatro hojas están hoy perdidas (Gonzalo García 2018: 202), por lo que lo único que puede consultarse es el facsímil que publicó Rodríguez-Moñino (1962: 165-172). El bibliógrafo extremeño, además, ya sugirió la atribución de esas hojas al taller barcelonés de Amorós (1962: 48), ahora confirmada por Lamarca (2015: 323). 


\section{del Cancionero general"'.}

La intuición de Rodríguez-Moñino con Valencia no me parece desacertada, ya que hay en efecto varios aspectos que hablan en favor de esa ciudad como posible lugar de impresión para la princeps de nuestro Libro: allí no solamente habían aparecido las dos primeras ediciones del Cancionero general, sino también, en 1505, la Oratio luculenta de Proaza, donde aparece uno de los romances del Libro; también me parece un lugar factible donde situar la aparición del villancico Si pena sentís, del que además de su presencia en el Libro de cincuenta romances solo conozco otra documentación en 19CF (Dutton 1990-1991). La posibilidad de que el Libro fuera una derivación de la sección de romances del Cancionero general, sin embargo, me parece bastante más discutible.

Como ya hemos dicho, en esa sección de la compilación de Castillo se contienen una cuarentena corta de romances. Las composiciones que han llegado hasta nosotros en las hojas conservadas del Libro son las siguientes: Todas las gentes dormian 1v. (Romance), Durmiendo estaua el cuydado 2v. (Romance), No puede sanar ventura 2v. (Villancico), Valēcia ciudad antigua 2v. (Romance), Pues que dios te hizo tal 3r. (Villancico en oración/por desecha), Yo mestaba reposando 3v. (Romance), Gritādo va el caballero 3v. (Romance), No quiero mundo vivir 4v. (Desecha), Fuente fria fuente fria 4v. (Romance) y Si pena sentis 4v. (Villancico).

Todos estos textos - con excepción del primero, Todas las gentes dormían, del romance de Juan del Encina Yo me estaba reposando y del villancico final, Si pena sentís - aparecen en el Cancionero general, lo cual, junto con la mención en el título del Libro de que los romances van junto con sus villancicos y desechas parecería, en principio, hablar en favor de una relación más o menos directa con la obra de Castillo. Pero una comparación de estos textos con las versiones del cancionero - en sus respectivas ediciones de 1511, 1514, 1517 y 1520 - así como con las versiones de esos romances aparecidas en pliegos sueltos (todos los textos salvo Si pena sentís están documentados en ellos ${ }^{8}$ ) revela que los textos del Libro son más cercanos a los primeros que a los segundos.

Obviamente, para valorar correctamente este aspecto, deberíamos conocer el contenido del resto del volumen. No podemos saber qué textos contenía la edición primitiva, pero sí podemos, creo, esbozar su perfil partiendo de los añadidos de Carles Amorós. Como ya hemos dicho, al vuelto de la primera hoja encontramos la siguiente nota: "Aqui comiençan cincuenta romāces en los cuales han ( sic) añadidos los siguientes romāçes. El romance de Calisto y Melibea. Otro q comiença En las salas de Paris. Otro d Guarinos. Otro de Gayferos. Otro al conde de Oliua. Otro del conde Claros. Otros

\footnotetext{
7 "el contener el romance de Proaza y el enderezado al Conde de Oliva nos hace sospechar si la, o las ediciones antiguas fueron hechas por primera vez en Valencia y como reimpresión con aumentos y estructura nueva de los poemas aparecidos en el Cancionero general" (1969: 76). En esto insiste también en la nota que acompaña a la descripción bibliográfica, donde escribe: "La inclusión del romance de Proaza en tercer lugar, quizá indique a Valencia como la ciudad en que se estampó el volumen por vez primera, tal vez como una derivación del apartado de romances del Cancionero general" (1969: 237).

8 Pues que Dios te hizo tal no aparece registrada en los índices del Nuevo Diccionario ni del Suplemento, pero es más que posible que apareciera también en la edición exenta del romance de Proaza que registra Colón, RM450.
} 
tanbien de amores. Otro de la reyna helena. Otros de paris y las tres deeses. Y muchos otros romances."

Esos romances serían los siguientes: en primer lugar, el romance de Calisto y Melibea debe ser sin duda el que comienza Un caso muy señalado. En las salas de Paris es también romance conocido por numerosos testimonios, como veremos más adelante. El romance de Guarinos, por su parte, suele identificarse con el que comienza Mala la hubisteis franceses, mientras que del de Gayferos generalmente se supone que era el de Asentado está Gayferos. Le seguirían Yo me parti de Valencia (Romance al Conde de Oliva) y el del Conde Claros, Media noche era por filo. Los dos con que se cierra la enumeración, finalmente, serían por este orden el de Reina Elena, reina Elena y el de Por una linda espesura. Ignoramos, por otro lado, cuales pudieran ser los que se indican como "tanbién de amores".

Como puede verse, estos romances no son los típicos textos de cancionero. Además, si sumamos los versos de las versiones más largas y de las más cortas conocidas de todos estos romances, el número máximo y mínimo de versos que resulta es de 2808 y 2505 (Garvin 2015: 43). La edición barcelonesa del Libro incluye 37 líneas de texto lo que, al estar impreso a dos columnas, supone un total de 74 versos por cara. Así, contando únicamente el texto de los romances, la edición barcelonesa necesitaría entre 4,3 y 4,7 pliegos de a cuatro hojas para dar cabida a esos añadidos, a lo que habría que sumar el espacio dedicado a los titulillos, la probable presencia de grabados y esos romances desconocidos "de amores", probablemente llegásemos incluso a los cinco pliegos. Ahora bien, si hacemos los mismos cálculos con los romances del Cancionero general nos encontramos con un dato que me parece suficientemente elocuente: juntando todas las composiciones de la sección de romances de 1511 - es decir, los romances, pero también todos los villancicos y las desechas - más el romance En las más altas confines, que aparece al principio del cancionero y el Cabe la isla del Elba, llegamos a un total de 2515 versos, un número casi idéntico al de los romances añadidos y que, por tanto, ocuparía el mismo espacio tipográfico que estos. Si la edición princeps fuera, como sugirió Rodríguez-Moñino, un "derivado" de la sección de romances del Cancionero de Castillo - y entiendo por "derivado" un impreso que se nutre fundamentalmente de esas páginas - el espacio destinado a los añadidos en la edición barcelonesa sería anormalmente extenso, ya que implicaría un $50 \%$ de ese supuesto original.

Tiene mucho más sentido, en cambio, suponer que los añadidos de Amorós siguen más o menos la línea temática de la princeps, de modo que al menos una buena parte de los cincuenta romances serían novelescos, verosímilmente carolingios en su mayoría, ya que estos son los que más se habían difundido en pliegos. El Libro original debía tener, en consecuencia, una longitud material suficiente para que los añadidos pudieran considerarse precisamente como eso: como adiciones a un cuerpo anterior suficientemente

$9 \quad$ En el catálogo del librero muniqués Jaques Rosenthal en el que se anunciaba el Libro de cincuenta romances se mencionaba en el mismo lote - que el Duque de T'Serclaes compró entero - bajo el $\mathrm{n}^{\circ} .55$ un manuscrito de hacia 1720 con el título „Romances amorosos“ (Gonzalo García 2018:189) sin que podamos saber si quizá este pudiera tener alguna relación con los romances que aquí aparecen, pues el manuscrito se halla en paradero desconocido. Quede apuntada la sospecha a la espera de futuros descubrimientos. 
amplio. Esto no está necesariamente en relación directa con el número de textos, pues hay romances muy cortos y otros muy largos: solamente el Conde Dirlos, con 1365 versos, ocupa la mitad de espacio tipográfico que toda la sección del Cancionero general junta. Pero no sé hasta qué punto debemos creer en la cifra redonda de cincuenta. Quizá sí para la princeps, pero no para el Libro conservado. En cualquier caso, no parece que el criterio de Amorós haya sido el de la exhaustividad que sí guiaba en gran parte a Martín Nucio. Recordemos que el impresor antuerpiense se justificaba, en el prólogo a la primera edición del Cancionero de romances, escribiendo aquello de "puede ser que falten aqui algunos, aunque muy pocos", mientras que en la edición barcelonesa parece haber primado el criterio de la novedad, que ya se anuncia en la portada cuando se dice "Entre los quales ay muchos dellos nueuamente añadidos: que nunca en estas tierras se han oydo".

Creo que el análisis de los textos conservados, de los añadidos anunciados y de los romances que podemos suponer al cuerpo original nos están hablando de los pliegos sueltos como base textual del Libro. Y creo que por esa vía podemos comprender algo mejor la materialidad del original. De hecho, las cuatro hojas conservadas no dejan de ser eso: un pliego suelto y podemos suponer que los cuadernos que faltan eran también - en su constitución y presentación - pliegos sueltos incorporados al Libro. Y con esto no me refiero únicamente a la procedencia de los textos: creo que el Libro de cincuenta romances pudo formarse por adición de pliegos. Aquí habría una diferencia fundamental con Nucio: también las fuentes fundamentales del cancionero de Amberes fueron los pliegos sueltos (Garvin 2016), pero Nucio - aunque en ocasiones mantiene el orden en que los romances aparecen en su fuente - se esforzó por ordenar los romances que sacaba de los pliegos, de modo que estos ofrecían solamente los materiales (Garvin 2006: 165-233). El Libro, por su parte, parece haber operado de un modo más directo, tomando de los pliegos no solamente los romances y textos poéticos que ofrecían, sino siguiéndolos también en su materialidad.

Si la edición barcelonesa procede de una princeps anterior, hemos de suponer que Amorós, como suele ser habitual en estos años cuando se reedita un impreso anterior, intentó reproducir o al menos mantener el aspecto original de su modelo. Esta práctica, si tomamos la hipótesis de Rodríguez-Moñino de Valencia como posible lugar de impresión de la princeps, ha permitido plantear la posibilidad de que el impresor de esa primera edición quizá fuera Joan Jofré (Garvin 2015: 41), ya que las figuritas que emplea Amorós para el Libro recuerdan mucho a las que utilizó el impresor valenciano, además de en otras obras, en su edición de la Celestina de 1514, que el propio Amorós editó en 1525, misma fecha que se le supone al Libro.

El diseño de la portada no corresponde al de un pliego, sino al de obras de mayor extensión ${ }^{10}$. En los primeros - ya lo hemos visto más arriba en la cita de Norton y Wilson - el grabado va colocado debajo del título y precede al texto que, generalmente en dos columnas, comienza ya en esa primera hoja. En el Libro, en cambio, el título completo

10 No se me escapa aquí que algunos pliegos sueltos, incluso tempranos, como por ejemplo RM408, salido de los talleres de J. Cromberger c. 1520 (Norton 1978: n. 946), tienen también ese diseño. 
y los dos grabados - galán con instrumento de cuerda y doncella - van enmarcados por una orla, formada de diversos trozos, sin que aparezca texto poético ninguno. Este sería también, suponemos, el aspecto externo de la princeps. El vuelto de esa primera hoja, sin embargo, sí es idéntico en su diseño al de muchos pliegos. Idéntico porque responde a esa misma morfología que acabamos de describir y ello pese a que estamos en el vuelto de la primera hoja de un impreso mayor y no en la portada de un pliego. Allí esta disposición obedece a una función específica, pero en nuestro Libro esa presencia parece deberse a la fuente empleada. Quizá en Amorós aún por dependencia de la edición original, pero allí ya sin duda por los materiales empleados. Tal dependencia respecto para con los pliegos queda, según creo, muy clara si comparamos este vuelto con un pliego como RM653, impreso en Burgos por Fadrique Biel de Basilea "c.1515-1519" (Fernández Valladares 2005: $n^{\circ}$ 96). La enorme similitud iconográfica - desde el uso de la $A$ capitular al inicio del título a la distribución de los grabados - viene reforzada por el hecho de que el primer texto sea en ambas hojas el Todas las gentes dormían. Si colocásemos ese vuelto de la primera hoja del Libro junto a un pliego cualquiera, como el propio RM653, el único elemento que nos permitiría notar que el Libro no es un pliego suelto común es la cantidad de romances que se anuncian en el título, demasiados para las cuatro hojas de que comúnmente se componen estos impresos.

Llegados ya a esos títulos con los que se anuncian los romances añadidos, hemos de notar que coinciden en su formulación con las informaciones que aparecen en los pliegos cuando son estos los romances que contienen. Hemos mencionado arriba la nota que aparece al vuelto. Pues bien, el "romance de Calisto y Melibea" del Libro (Un caso muy señalado), aparece en RM1042", el único pliego que lo transmite, como "Romance nueuamente hecho de Calisto y Melibea que trata de todos sus amores y de las desastradas muertes suyas- y de la muerte de sus criados Sempronio y parmeno y de la muerte de aquella desastrada muger Celestina intercessora en sus amores". "Otro q comiença En las salas de Paris." es en testimonios como RM1084 "Siguese un romance: el qual cuenta el desafio que hizo montesinos a oliveros en las salas de paris: hecho por juan del campo: con vn romance de los doze pares que dize: en missa esta el emperador: con vn villancico" y en otros como RM352.3 "Glosa sobre el romance en la salas de parijs". Mala la hubisteis franceses se conoce y documenta como el "de Guarinos", así por ejemplo en RM705 "Aqui comiença vn romance del conde Guarinos almirante de la mar: trata como lo catiuaron los moros" o en RM1026 "Romance del conde guarinos almirante de la mar / nueuamente trobado como lo catiuaron moros. Y vnas coplas de madalenic (sic)". Asentado esta Gayferos - si este fuera el romance al que se refiere con el título - es en la inmensa mayoría de testimonios conocidos el "romance de Gayferos": "Romance de don Gayferos: y trata de como saco a sus esposa que estaua captiua en tierra de moros" (RM994, RM997, RM995, RM100). Yo me partí de Valencia suele titularse en la tradición impresa con el nombre de su destinatario, el Conde de Oliva, igual en nuestro Libro que en RM658 "Aqui comiençan diez maneras de romances con

11 Pliego impreso en Sevilla por Jacobo Cromberger en 1513 (Norton 1978: n. 836), conservado hoy en la Biblioteca Menéndez Pelayo de Santander. 
sus villancicos: y aquesta primero fue hecho al conde de Oliua" o en RM668 "Aqui comiençan onze maneras de romances. Con sus villancetes y aqueste primero romance fue fecho al Conde de oliua". Durmiendo está el conde claros es, en los dos pliegos que lo transmiten (RM76 y RM423) el "Romance del conce claros", igual que en el Libro. Y exactamente lo mismo cabe decir del romance "de la reyna Helena", que en RM1011 bis es, por ejemplo "Romance dela reyna Elena con la glosa del romance de Eneas" o en RM1048, más escueto, "romance de a (sic) reyna Helena". Incluso el que en el Libro se denomina "romance de Paris y las tres deeses" podría haber tenido una forma similar en los pliegos, ya que el título con el que aparece en el Cancionero de romances es "Romance de Paris del juyzio que dio quando las tres deesas le hallaron durmiendo". Mención aparte merecen los "Otros tanbien de amores", que no podemos identificar con ningún romance concreto, aunque la referencia es común, por ejemplo en pliegos como RM191, que Colón anota como "Petri Fernandez. Romance de amores en coplas".

Creo que este listado - a pesar de que nos movemos en un terreno muy especulativo, debido a las pérdidas - refuerza la suposición de que el Libro se compuso principalmente por adición de pliegos, debiendo entender esto en un sentido mucho más literal de lo que sucede, por ejemplo, con el Cancionero de romances. El Libro no tomó de los pliegos solamente su contenido, sino también - salvando las distancias - su constitución.

Podemos dar así casi por seguro tanto que el Libro de cincuenta romances, en sus al menos dos ediciones, constituía un volumen compuesto por varios pliegos - en los dos sentidos de la palabra - como que el diseño de sus páginas imitaba el de estos. De modo que resulta muy tentador pensar que algunos de los pliegos sueltos que hoy conocemos pudiera haber sido la fuente real del Libro o, incluso más, creer que alguno de esos pliegos u hojas sueltas pudieran ser partes perdidas de este, ya que, insistimos, solo se conservan las cuatro primeras hojas. Lamarca, por motivos muy distintos a los que aquí vamos exponiendo, ha propuesto en su estudio sobre la imprenta en Barcelona considerar el pliego RM1063, incompleto - se conserva una sola hoja - e impreso también por Amorós, además de provenir igualmente de la colección del Marqués de Morbecq, como "continuación" del Libro, es decir, como hoja perteneciente al mismo conjunto. Los motivos que expone Lamarca son los siguientes: "crec que malgrat que és incomplet, s'ha d'observar que es llegeix „Siguense“ al recto del f. Av i a l'incipit del verso del f. Aj: „Otro de gayferos“" es tracta d"una sola obra i no de dues tal i com creuen Norton, Askins i Rodríguez-Moñino.” (2015: n 215). Es una hipótesis sin duda muy sugerente, aunque de difícil verificación. El pliego - en realidad, la hoja, pues como he dicho se conserva solo una, la primera - ha sido siempre objeto de controversia. Perteneció a la colección del Marqués de Morbecq y por tanto, anteriormente a la del Duque de T'Serclaes, su padre, y, en última instancia, al librero muniqués Jaques Rosenthal. Diego Catalán supuso que esta hoja (RM1063) iría unida a otra hoja suelta de la misma colección, RM1170. Ahora, ¿cómo llega Catalán a esa conclusión?? ${ }^{12}$. Al

12 Los datos que he encontrado al respecto proceden de unas notas al pie en dos páginas de su estudio sobre La dama y el pastor, donde se refiere a estos dos pliegos como "pliego suelto incompleto". En la nota 47, Catalán nos dice que Rodríguez-Moñino "edita el romance de Gayferos en las págs. 173-174 y nuestro romance en la pág. 340 sin identificarlo como parte del pliego Siguense dos romances de Gayferos" (Catalán 1977: 39). 
parecer, cuando Ramón Menéndez Pidal logró que se fotografiara esa colección - algo que, según cree Mercedes Fernández Valladares, sucedió en 1928 (2016: 169-170) - esa hoja y nuestro RM1063 iban juntos; eso es al menos lo que se desprende de la argumentación de Diego Catalán cuando escribe que: "Entre la segunda hoja [de RM1063], en que figura el romance de Gayferos [...] y aquella cuyo verso se incluye nuestro romance, que comienza con los últimos versos del romance de Diego de Acuña 'Alterado el pensamiento' [...] faltaban hojas cuando los fotografío Menéndez Pidal” (1977: 39).

Ahora bien, Rodríguez-Moñino ya indicó, en el prólogo a los pliegos de Morbecq respecto de los pliegos del Marqués que "tres son hojas sueltas (núms. XXX, XXXI y XXXII) que se hallaban mal encuadernadas con otros fragmentos y hemos separado para darles volumen independiente" (1962: 32), algo en lo que insiste cuando habla de "...tres fragmentos de pliegos, trastocados en el lote procedente de Rosenthal y que hoy se hallan unidos a otros con los cuales nada tienen que ver" (1962: 37). Montserrat Lamarca, por su parte, no identifica esa hoja suelta (RM1170) como producto de la imprenta barcelonesa, por lo que parece prudente descartar la identidad entre RM1170 y RM1063.

Por otra parte, lo que sí conocemos son otros pliegos con esos dos romances de Gayferos, ediciones en la misma tradición que RM1063, que pueden ayudarnos a resolver el problema. RM1062 y RM1064 son dos pliegos bifolios, titulados precisamente igual que nuestra hoja: "Siguense dos romances de Gayferos", lo que en principio parece resolver sin mayores problemas el misterio: RM1063 sería también un pliego de dos hojas y tendría el mismo contenido. Ahora bien, conocemos otro pliego, RM706, en el que también aparecen estos dos romances, pero esta vez es un pliego de cuatro hojas. Es un pliego bastante tardío para nuestros propósitos, ya que fue impreso por Felipe de Junta, c. 1564-1570 (Fernández Valladares 2005: n 583) y el título es algo distinto: "Aqui comiença un romance del conde Guarinos Almirante de la mar: y trata como lo captiuaron los moros. Y otros dos romances de Gayferos: en los quales se contiene como mataron a don Galuan. Y unas coplas hecas por Rodrigo de Reynosa”. Sin embargo, si miramos en el interior, vemos que pese a ser un pliego de cuatro hojas, al vuelto de la segunda los dos romances de Gayferos se anuncian así: "Siguense dos romance de Gayferos en los quales se contiene como mataron a don Galuan"13. Esto alimenta la sospecha de que en algún momento de la transmisión, lo que en principio eran dos pliegos de dos hojas pudiera haber pasado a ser un pliego de cuatro. Refuerza mucho esta sospecha que del romance de Guarinos también conozcamos una edición de solamente dos hojas en un pliego (RM1064, hoy en la Biblioteca Nacional de Madrid) que en su momento perteneció a la colección de la Condesa de Campo Alanje, en cuyo volumen aparecía contiguo precisamente con nuestro RM1062 (Rodríguez-Moñino 1963); de hecho, mucho antes, Huarte y Castañeda, al editar en facsímil algunos pliegos de la Biblioteca Nacional, ya habían supuesto que esos supuestos pliegos bifolios en realidad irían unidos (Castañeda; Huarte 1933: 10).

13 Hay edición facsímil del pliego (Menéndez Pidal 1961: I, 22) 
Y si volvemos ahora al texto del vuelto de nuestro Libro, donde se indican los romances añadidos veremos que el de Guarinos y el de Gayferos se mencionan precisamente en ese orden: "Otro de Guarinos. Otro de gayferos". A la sospecha de que existieron pliegos tempranos con los romances en ese orden se añade ahora la de que Amorós pudiera haber añadido uno de esos pliegos directamente al Libro y, por tanto, que RM1063 sea en efecto una hoja de ese pliego o, mejor dicho, una hoja del propio Libro. Lo que se anuncia como "Otro de gayferos", serían en realidad "Otros de Gayferos", es decir, los dos romances que contiene el pliego de dos hojas original titulado "Siguense dos romances...": Estabase la condesa y Vamonos dijo mi tio y no Asentado está Gayferos, como hasta ahora se ha supuesto. El error es menos extraño de lo que pudiera parecer. Quien se tome la molestia de analizar el título interior en la reproducción facsimilar, verá no solo que ese mismo error ya se comete una vez - si bien a la inversa - al referirse a "Otros de Paris", cuando en realidad el romance del jucio es solo uno, sino también que en ese mismo espacio tipográfico abundan las terminaciones en -os. La palabra que precede al otro que suponemos plural es Guarinos y la que le sigue tras el de es Gayferos; en la vertical tiene justo debajo Claros y Otros. Nada extraño por tanto que la $-s$ final diera un salto.

Todo esto vendría a confirmar por tanto que el Libro se formó como un conjunto coherente de pliegos (muchos de ellos bifolios), que en ediciones posteriores - o en su edición posterior, que son esas cuatro (¿cinco?) hojas que conservamos - fue aumentado siguiendo un criterio muy similar. Si esto fue así, el Libro no puede considerarse materialmente como una derivación de la sección de romances del Cancionero general, pero eso no significa que no tenga deudas con ella. Hay que tener en cuenta que, aunque lo hubiera pretendido, el Libro probablemente no hubiera podido ser una derivación de ese tipo, al menos abiertamente. El Cancionero general apareció con privilegio para diez años, mencionado tanto en la edición de 1511 como en la de 1514. Durante ese tiempo, la única obra que con propiedad puede denominarse derivación de una sección del Cancionero general es el Cancionero de obras de burlas. Este cancionero fue impreso por Juan Viñao (o Vinyau) en 1519, cuando el privilegio del Cancionero general aún tenía vigencia, aunque hay que tener en cuenta, como señala Martínez Romero que lo más probable es que Viñao, para la impresión del Cancionero de obras de burlas, llegara "a algún tipo de acuerdo con Costilla -o los inversores del Cancionero general" (2015: 133). El resto de obras dependientes de modo más o menos directo de la compilación de Castillo - la Guirnalda esmaltada de Juan Fernández de Constantina, el Dechado de galanes, el Espejo de enamorados o el Cancionero de galanes - aparecen siguiendo una estrategia editorial distinta (por ejemplo escondiendo la autoría original), aunque su relación con la obra de Castillo es obvia. También lo es la relación entre ellas, tanto materialmente, como por el espacio editorial que vienen a cubrir.

La reducción de la transmisión impresa del romancero a tres tipos de transmisores es plenamente justificable, pero no deja de ser reduccionista cuando deja de lado - no nominal, pero sí tipológicamente - a estos cancionerillos (sobre los que ni siquiera hay seguridad sobre cómo deben denominarse) de la primera mitad de siglo, como el Dechado de Galanes, el Espejo de enamorados, la Guirnalda esmaltada, etc. 
Es entre ellos donde hay que incluir al Libro de cincuenta romances. En el contexto de la transmisión del romancero impreso es extraño, porque no es como los demás: es demasiado grande para ser un pliego y es demasiado breve para ser un romancero (y esto último obviando que faltan veinte años para que aparezca un romancero...); sin embargo, si lo contemplamos en este otro contexto de los cancioneros menores, se entiende mucho mejor su condición, una condición que sin duda no puede calificarse de anómala.

\section{BIBLIOGRAFÍA}

ASKINS, A.L.F.; INFANTES, Víctor (2014): Suplemento al Nuevo Diccionario bibliográfico de pliegos sueltos poéticos (Siglo XVI). de Antonio Rodríguez-Moñino. Edición de Laura Puerto Moro. Madrid: Editorial Academia del Hispanismo.

BELTRAN, Vicenç (2006): "Imprenta antigua, pliegos poéticos, cultura popular (-1516)", en Pedro Cátedra (dir.), Eva Belén Carro Carvajal et al., La literatura popular impresa en España y en la América colonial. Formas \& temas, géneros, funciones, difusión, historia y teoría. Salamanca: Seminario de Estudios Medievales y Renacentistas - Instituto de Historia del Libro y de la Lectura, 363-379.

CASTAÑEDA, Vicente; HUARTE, Amalio (1933): Nueva Colección de pliegos sueltos. Madrid: Tipografía de Archivos.

CATALÁN, Diego (1977): La dama y el pastor. Romance; villancico; glosas. Madrid: Gredos.

DUTTON, Brian (1990-1991): El cancionero del siglo XV (ca.1360-1520). Salamanca: Universidad de Salamanca.

FERNÁNDEZ VALLADARES, Mercedes (2005): La imprenta en Burgos (1501 1600). Madrid: Arco Libros.

(2016): "Lapesa, biblógrafo ,pliegosueltista'. Un intento madrugador de datación de los pliegos sueltos de romances", Abenámar. Cuadernos de la Fundación Ramón Menéndez Pidal, 1, 1,153-186.

GARVIN, Mario (2006): "Sobre sociología de la edición: el orden del Cancionero de romances. (s.a y 1550)“, Pedro Cátedra (dir.), Eva Belén Carro Carvajal et al., La literatura popular impresa en España y en la América colonial. Formas \& temas, géneros, funciones, difusión, historia y teoría. Salamanca: Seminario de Estudios Medievales y Renacentistas - Instituto de Historia del Libro y de la Lectura, 491-502.

(2007): Scripta Manent. Hacia una edición crítica del romancero impreso (Siglo XVI). Madrid-Frankfurt: Iberoamericana.

(2015), „El Libro de cincuenta romances: historia editorial de un impreso perdido", Zeitschrift für Romanische Philologie, 131 (1), 36-56.

(2016): „Martin Nucio y las fuentes del Cancionero de Romances“, Ehumanista, 32, 288-302. 
(2019): „Fuentes impresas del romancero: el caso de los pliegos poéticos sevillanos de la primera mitad del siglo XVI“, en Pragmática y metodología para el estudio de la poesía medieval, Josep Lluís Martos y Natalia Mangas, Alacant, Universitat d'Alacant, Colección Cancionero, Romancero e Imprenta, 2., 235-252.

GONZÁLEZ CUENCA, Joaquín (Ed.) (2004): Cancionero general. Madrid: Castalia. Nueva Biblioteca de Erudición y Crítica.

GONZALO GARCÍA, Consuelo (2018): El legado bibliográfico de Juan Pérez de Guzman y Boza, Duque de T'Serclaes de Tilly. Aportaciones a un catálogo descriptivo de relaciones de sucesos (1501-1625). Madrid: Arco-Libros.

INFANTES, Víctor (1988): „Los pliegos sueltos poéticos: constitución tipográfica y contenido literario", López-Vidriedro, María Luisa \& Cátedra, Pedro M. (ed.), El libro antiguo español (Actas del primer coloquio internacional, Madrid, 18 al 20 de diciembre de 1986). Salamanca, Universidad de Salamanca, 237-248.

(1989): „Edición, literatura y realeza, apuntes sobre los pliegos poéticos incunables", en Literatura hispánica, Reyes Católicos y descubrimiento. Actas del congreso internacional sobre literatura hispánica en la época de los Reyes Católicos y el descubrimiento, Manuel Criado de Val, Barcelona, PPU, 85-98.

LAMARCA, Montserrat (2015): La impremta a Barcelona (1501-1600). Barcelona: Generalitat de Catalunya.

MARTÍNEZ-ROMERO, Tomás (2015): "De la selección "De burlas" al Cancionero de obras de burlas en el contexto valenciano", en Las 'Obras de burlas' del Cancionero general de Hernando del Castillo. Las 'Obras de burlas' del Cancionero general de Hernando del Castillo, A. Cortijo Ocaña; M. Rubio Árquez, Santa Barbara, Publications of Ehumanista n. 10, University of California,

MENÉNDEZ PIDAL, Ramón (1961): Pliegos poéticos espanoles en la Universidad de Praga. Madrid: Joyas Bibliográficas.

NORTON, F.J.; WILSON, E.M. (1969): Two Spanish Verse chap-books. Cambridge: Cambridge University Press.

PIACENTINI, Giuliana (1981): Ensayo de una bibliografía analítica del romancero antiguo.los textos (siglos XV y XVI). Vol. I. Los pliegos sueltos. Pisa: Giardini. (1986): Ensayo de una bibliografía analítica del romancero antiguo. II. Cancioneros y Romanceros. Pisa: Giardini.

PUERTO MORO, Laura (2006): "Hacia la definición de una retórica formal para el pliego suelto poético (1500-1520)", Cátedra, Pedro M. (dir); Carro Carvajal, Eva Belén (ed.), La literatura popular impresa en España y en la América colonial. Formas y temas, géneros, funciones, difusión, historia y teoría. Salamanca, Seminario de Estudios Medievales y Renacentistas, SEMYR, Inst. de Historia del Libro y de la Lectura, 543-561.

(2012): "El universo del pliego poético postincunable (del despegue de la literatura popular impresa en castellano)", Ehumanista, 21, 257-305. 
RODRÍGUEZ-MOÑINO, Antonio; ASKINS, Arthur Lee Francis (1973): Manual bibliográfico de cancioneros y romanceros. Siglo XVI. Madrid: Castalia.

RODRÍGUEZ-MOÑINO, Antonio (Ed.), CASTILlO, Hernando del (1958): Cancionero general / recopilado por Hernando del Castillo (Valencia, 1511); sale nuevamente a la luz en facsímile por acuerdo de la Real Academia Española; con una introducción bibliográfica, índices y apéndices por Antonio Rodríguez Moñino. Madrid: Real Academia Española.

RODRÍGUEZ-MOÑINO, Antonio (1962): "Los pliegos poéticos de la colección Campo de Alanje en la Biblioteca Nacional de Madrid (siglo XVI)", Romance Philology, 17, 2,373-380.

(1970): Diccionario Bibliográfico de pliegos sueltos poéticos. Madrid: Castalia. (1997): Nuevo Diccionario Bibliográfico de pliegos sueltos poéticos (Siglo XVI). Edición actualizada y corregida por A.L.F. Askins y V. Infantes. Madrid: Castalia. Nueva Biblioteca de Erudición y Crítica.

\section{PERFIL ACADÉMICO-PROFESIONAL}

Licenciado en Filología Hispánica (Universidad Autónoma de Barcelona). Doctor en Filología Románica (Universidad de Colonia, Alemania). Profesor de la Universidad de Constanza (Alemania).

Fecha de recepción: 29/02/2020

Fecha de aceptación: 30/04/2020 